\title{
ANALIZA STOSOWANYCH TECHNOLOGII OBRÓBKI POWIERZCHNI ZAMKA TARCZY SPRĘŻARKI I TURBINY GAZOWEJ
}

\begin{abstract}
Powierzchnie elementów połączeń zamkowych w turbinie i sprężarce są jednymi $\mathrm{z}$ najbardziej obciążonych powierzchni podczas pracy silnika turbinowego. Obecność agresywnego środowiska (gorący gaz z popiołem i domieszkami znajdującymi się w paliwie), wysoka temperatura pracy, ciśnienie, obciążenia od działania sił odśrodkowych, gazodynamicznych oraz powstające drgania wywołują wiele procesów prowadzących często do uszkodzenia połączenia zamkowego, a w efekcie nawet awarii lub zniszczenia silnika turbinowego. Wymienione czynniki wpływające na powierzchnie połączeń zamkowych prowadzą do wzrostu naprężeń i napięć kontaktowych, aktywizacji procesów zużycia frettingowego, powodują również erozję i pękanie zmęczeniowe. Najczęściej stosowanym typem połączenia łopatki z tarczą wirników sprężarki jest zamek trapezowy lub tzw. ,jaskółczy ogon”, dla turbiny zaś - jodełkowe połączenie zamkowe. W procesie projektowania i wytwarzania zamka należy szczególnie uwzględnić stabilną pracę zespołu wirnikowego sprężarki i turbiny oraz żywotność całego silnika oraz wziąć pod uwagę: wysokie wymagania dotyczące składu oraz jakości materiałów tarczy i łopatek, niską obrabialność tych materiałów, skomplikowany kształt i wysokie wymagania dotyczące dokładności, a także wzajemnego położenia powierzchni oraz jakość warstwy powierzchniowej zamka. Takie wymagania można spełnić za pomocą różnych metod obróbki skrawaniem (przeciąganie, frezowanie), obróbki elektrochemicznej (ECM) lub elektroerozyjnej (EDM). Metoda obróbki elektrochemicznej zamka ma wiele zalet w stosunku do obróbki skrawaniem, m.in.: możliwość obróbki materiałów przewodzących prąd z różnymi właściwościami mechanicznymi, zapewnienie wysokiej jakości warstwy powierzchniowej, dużą produktywność przy długim okresie eksploatacji elektrody. Dokładność obróbki zamków metodą ECM jest jednak bardzo niska. Metoda przeciągania pozostaje więc jedną z najczęściej używanych, a na etapie wykańczania - jedyną możliwą metodą tworzenia dokładnego zamka z wysoką jakością warstwy powierzchniowej.
\end{abstract}

Słowa kluczowe: połączenia zamkowe, dokładność kształtu, jakość warstwy powierzchniowej, przeciąganie tarczy, żywotność silnika turbinowego

\section{Wprowadzenie}

Rozwój branży okrętowej, lotniczej, energetycznej i innych branż przemysłu maszynowego jest ściśle związany z wprowadzaniem nowoczesnych technologii

1 Autor do korespondencji/corresponding author: Olha Dvirna, Akademia Morska w Gdyni, ul. Morska 81-87, 81-225 Gdynia, tel.: +48608816161, e-mail: o.dvirna@wm.am.gdynia.pl 
obrabiania głównych elementów silników, do których produkcji stosuje się materiały o ulepszonych właściwościach fizycznych i mechanicznych.

Silnik turbinowy jako źródło lub przetwornik energii jest często stosowany w ciepłownictwie, okrętownictwie, lotnictwie, a także w transporcie naziemnym. Głównym elementem silnika determinującym jego parametry pracy jest turbina gazowa. Im wyższa robocza temperatura gazu w turbinie, tym na ogół bardziej ekonomiczna praca silnika, gdyż wraz z jej wzrostem zmniejsza się jednostkowe zużycie paliwa i powietrza na jednostkę mocy. W związku z tym, do produkcji głównych elementów turbiny należy zastosować nowe żaroodporne materiały oraz nowe metody i technologie ich obróbki.

Obecnie najczęściej stosowane w przypadku połączeń łopatek z obręczą tarczy są zamki typu ,jaskółczy ogon”. Wyróżniają się one prostotą konstrukcji i stosunkowo niewielką wysokością zamka, co umożliwia stosowanie tarczy ze zmniejszoną grubością obręczy. Z kolei taka konstrukcja tarczy umożliwia rozmieszczenie optymalnej liczby łopatek na obręczy w celu stworzenia kratki o wymaganej gęstości. Połączenia te mają jednak niską zdolność tłumienia drgań. Doświadczenie wynikające z eksploatacji silników wskazuje, że zasadnicza część uszkodzeń całkowitych i częściowych powstaje wskutek zjawiska zmęczenia przy drganiach roboczych łopatek, które tworzą ogniska pęknięć zmęczeniowych i stają się przyczyną uszkodzenia trzonu łopatki i występu tarczy. Badania dynamicznych właściwości połączeń zamkowych pokazują, że właściwie dla wszystkich typów łopatek drgania, bez względu na ich formę, nie zanikają u stopy łopatki, lecz rozprzestrzeniają się w głąb połączenia zamkowego (niezależnie od siły zacisku nie można wygasić drgań w zamku), co ostatecznie prowadzi do pojawienia się zjawiska frettingu [1].

Połączenia jodełkowe są w znacznie mniejszym stopniu podatne na takie negatywne procesy jak opisane powyżej, co wynika z równomiernego podziału obciążenia elementów profilu zamka. Pracują one poprawnie w przypadku gdy jest zapewniony właściwy kontakt powierzchni zamkowej łopatki i tarczy. Jednym z najważniejszych parametrów kontaktowego współdziałania połączeń zamkowych jest wielkość zbliżenia powierzchni łączących się elementów. Kontaktowe zbliżenie powierzchni odbywa się przez elastyczno-plastyczne deformacje wierzchołków chropowatości oraz leżących poniżej warstw. Na proces przejścia od deformacji elastycznych do plastycznych przy takim samym materiale ma znaczący wpływ jakość warstwy powierzchniowej (uszkodzenia powierzchni, chropowatość, znak i wartość naprężeń resztkowych, stopień umocnienia powierzchni itp.), zależnej od technologicznych metod obróbki powierzchni kontaktowych.

\section{Technologiczne metody obróbki połączeń zamkowych}

Typ zamka wybiera się w zależności od jego przeznaczenia, miejsca rozmieszczenia, stopnia turbiny i sprężarki oraz warunków pracy tarczy. Przy wyborze metody obróbki zamków należy uwzględnić właściwości używanych żarowy- 
trzymałych materiałów, ich obrabialność oraz dokładność wzajemnego położenia powierzchni połączeń zamkowych o skomplikowanym profilu. Obecnie stosuje się kilka metod obróbki połączeń zamkowych, wśród których można wyróżnić metody: obróbki skrawaniem (przeciąganie, frezowanie), obróbki elektrochemicznej (ECM) i elektroerozyjnej (EDM).

Spośród metod obróbki skrawaniem połączeń zamkowych najczęściej stosuje się metodę przeciągania. Przeciąganie jest to proces obróbki mechanicznej, w której cały naddatek obróbkowy usuwa się w czasie jednego przejścia narzędzia nazywanego przeciągaczem (stosowanego w produkcji wielkoseryjnej i masowej). Proces ten jest realizowany według dwóch schematów usuwania naddatku (generatorowego i profilowego) na poziomych oraz pionowych obrabiarkach różnych rodzajów i o odmiennej konstrukcji. Parametry skrawania przy przeciąganiu są wybierane w zależności od właściwości obrabianego materiału i wykonywanej operacji, a także technicznej charakterystyki obrabiarki. Kolejność usuwania naddatku zależy od typu obrabianego zamka (rys. 1.).

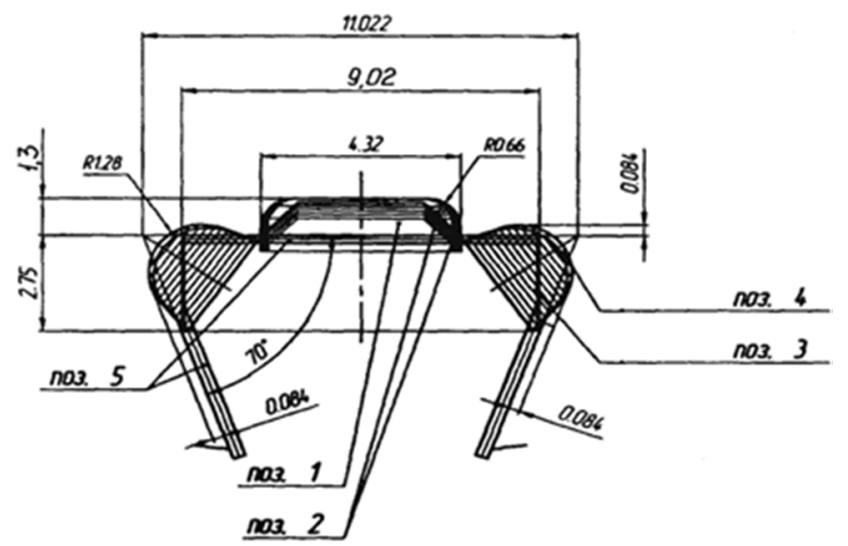

Rys. 1. Kolejność usuwania naddatku przy przeciąganiu

Fig. 1. Removal sequence of broaching operation

W ramach umowy o technicznej współpracy z Naukowo-Produkcyjnym Zespołem Budowy Turbin Gazowych „Zoria-Maszprojekt” (Ukraina) przeprowadzono wiele badań dotyczących zastosowania metod obróbki skrawaniem zamków tarcz wytwarzanych z żarowytrzymałej stali ЭП517-Ш [2, 3]. Mikrostrukturą kutych wzorców z tego materiału w stanie hartowania i odpuszczania w wysokiej temperaturze jest sorbit w charakterze martenzytu (rys. 2.). Chemiczny skład tej stali przedstawiono w tab. 1., a właściwości mechaniczne w tab. 2. 


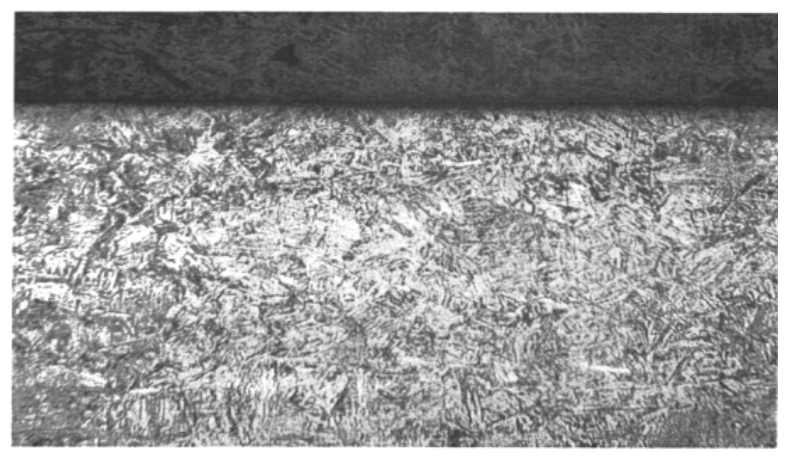

Rys. 2. Mikrostruktura wzorca ze stali ЭП517-Ш

Fig. 2. ЭП517-Ш steel sample microstructure

Tabela 1. Skład chemiczny stali ЭП517-Ш

Table 1. Chemical composition of ЭП517-Ш steel

\begin{tabular}{|c|c|c|c|c|c|c|c|c|c|c|c|c|c|}
\hline $\begin{array}{c}\text { Stal, } \\
\%\end{array}$ & $\mathrm{C}$ & $\mathrm{Cr}$ & $\mathrm{Ni}$ & $\mathrm{Mo}$ & $\mathrm{W}$ & $\mathrm{V}$ & $\mathrm{Nb}$ & $\mathrm{N}$ & $\mathrm{Fe}$ & $\mathrm{Si}$ & $\mathrm{Mn}$ & $\mathrm{S}$ & $\mathrm{P}$ \\
\cline { 8 - 13 } & & & & & & & \multicolumn{5}{|c|}{ nie więcej } \\
\hline ЭП517-Ш & 0,13 & 11,0 & 1,7 & 1,35 & 0,65 & 0,18 & 0,20 & 0,02 & & & & \\
& 0,18 & 12,5 & 2,1 & 1,65 & 1,0 & 0,30 & 0,35 & 0,08 & osn. & 0,5 & 0,5 & 0,015 & 0,03 \\
\hline
\end{tabular}

Tabela 2. Właściwości mechaniczne stali ЭП517-Ш

Table 2. Mechanical properties of ЭП517-Ш steel

\begin{tabular}{|c|c|c|c|}
\hline \multirow{2}{*}{ Obróbka cieplna } & \multicolumn{3}{|c|}{ Właściwości mechaniczne } \\
\cline { 2 - 4 } & $\begin{array}{c}\text { wytrzymałość, } \\
\mathrm{MPa}\end{array}$ & $\begin{array}{c}\text { granica plastyczności, } \\
\mathrm{MPa}\end{array}$ & $\begin{array}{c}\text { udarność, } \\
\mathrm{J} / \mathrm{cm}^{2}\end{array}$ \\
\hline Hartowanie $1120 \pm 15^{\circ} \mathrm{C}$ & 1090 & 935 & 128 \\
\hline Odpuszczanie $680 \pm 15^{\circ} \mathrm{C}$ & 1075 & 875 & 113 \\
\hline
\end{tabular}

Stal ЭП517-Ш ma dobre właściwości eksploatacyjne, jest o wiele tańsza od istniejących odpowiedników, posiada jednak wiele specyficznych właściwości fizyczno-mechanicznych, które obniżają jej obrabialność i utrudniają zastosowanie tradycyjnych metod obróbki. Podczas badania jakości powierzchniowej warstwy połączeń zamkowych tarcz turbin i kompresorów ze stali ЭП517-Ш (obrobionych metodą przeciągania) zostały ujawnione liczne uszkodzenia powierzchni zamkowych (rys. 3.). 

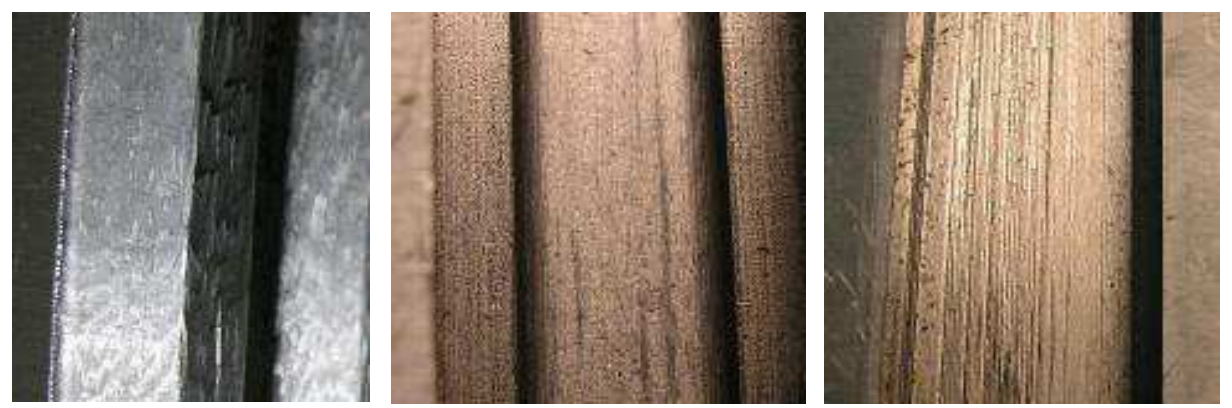

Rys. 3. Uszkodzenia obrabianej powierzchni

Fig. 3. Defects of the treated surface

(1)

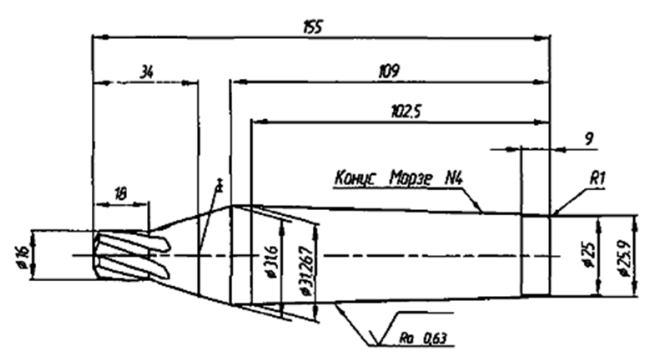

$\sqrt{\sin 25(V)}$

(2)

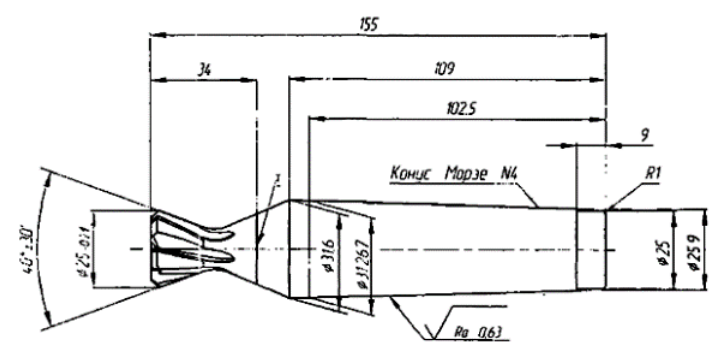

$$
\sqrt{\operatorname{sen} 25(V)}
$$

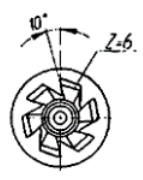

(3)
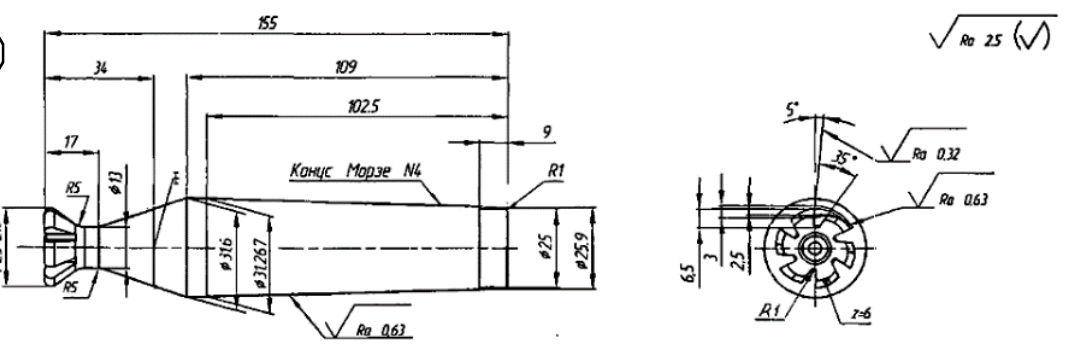

Rys. 4. Kolejność używania frezów

Fig. 4. Sequence of mills use 
W przypadku produkcji krótkich serii zamków z szeroką gamą obrabianych powierzchni można zastosować frezowanie jako alternatywną metodę obróbki połączeń zamkowych tarcz turbiny gazowej. Realizacja technologii frezowania zamków typu ,jaskółczy ogon” i ,jodła” we wzorcach ze stali ЭП517-Ш polegała na wyznaczeniu warunków otrzymania zamków o rozmiarach i jakości odpowiadających wymaganiom technologicznym oraz zasadom rysunku technicznego. W wyniku tego ustalono:

- schemat i kolejność obróbki,

- tryby skrawania,

- chropowatość obrabianych powierzchni,

- czas obróbki zamka.

Do wykonywania zamka był zaprojektowany i wytworzony komplet frezów palcowych o określonym kształcie i określonej geometrii części skrawających (rys. 4. i 5.). Frezowanie zamków typu jodełkowego realizowano przez dwie operacje: najpierw wycinanie zamka trapezowego, a następnie nadanie mu wymaganej formy (rys. 6.).

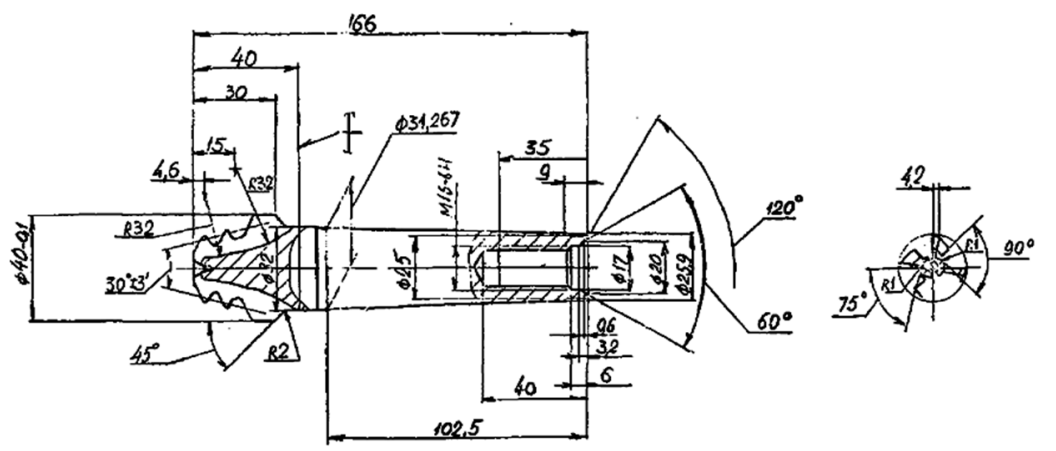

Rys. 5. Kształt ostatecznego frezu

Fig. 5. The shape of the finished mill

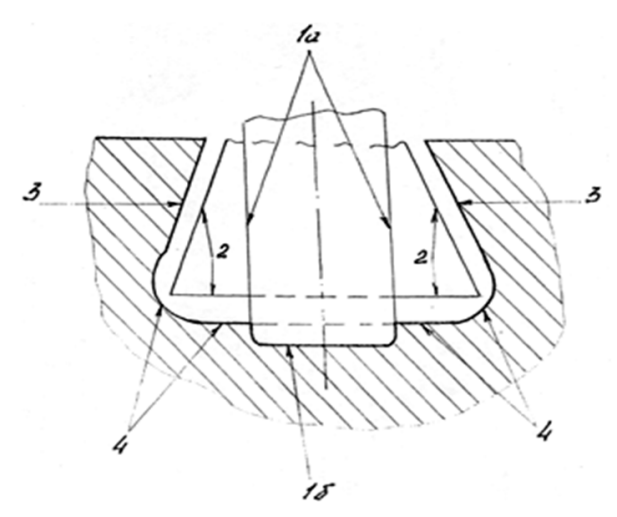

Rys. 6. Kolejność usuwania naddatku przy frezowaniu

Fig. 6. Removal sequence of milling operation 
Oprócz metod obróbki skrawaniem znane są również metody formowania zamków w tarczach zgodnie ze schematem obróbki elektroerozyjnej (EDM). Są one realizowane w dwóch wariantach: prostego oraz odwrotnego kopiowania. Ze względu na małe ścieranie elektrody i zadowalającą energochłonność (na poziomie frezowania), obróbkę elektroerozyjną w trybie elektroimpulsowym można rekomendować jako alternatywę dla frezowania dużych powierzchni o skomplikowanym kształcie.

\section{Wnioski}

W celu wstępnej obróbki zamków w wielkogabarytowych tarczach stosuje się metodę elektrochemiczną (ECM). Metoda obróbki ECM zamka pozwala znacznie zmniejszyć liczbę przeciągaczy w zestawie i ma wiele zalet w stosunku do obróbki skrawaniem:

- możliwość obróbki materiałów przewodzących prąd z różnymi właściwościami mechanicznymi,

- zapewnienie wysokiej jakości warstwy powierzchniowej,

- dużą produktywność,

- duży okres eksploatacji elektrody,

- umiarkowaną wartość elektrody.

Wadą tego rodzaju obróbki jest bardzo mała dokładność.

Metodę obróbki EDM można zastosować w przypadkach, gdy mechaniczna obróbka nie pozwala osiągnąć wysokiej wydajności oraz przy utrudnionym dostępie narzędzia do strefy skrawania. Powierzchniowa warstwa zamka tarczy po obróbce elektroerozyjnej nabiera zwiększonej twardości, przy czym środek zachowuje miękkość, co pozytywnie wpływa na eksploatacyjne właściwości tarcz. Na powierzchni mogą jednak występować pęknięcia, wywołane przez naprężenia rozciągające. Bardzo trudno jest zapewnić wymaganą chropowatość powierzchni. Taki rodzaj obróbki jest zalecany podczas operacji wstępnych i kształtujących w procesie usuwania większości naddatku. Zastosowanie metody przeciągania pozostaje zatem jedną z najczęściej używanych, a na etapie wykańczania - jedyną możliwą metodą tworzenia dokładnego zamka z wysoką jakością warstwy powierzchniowej [4].

\section{Literatura}

[1] Dvirna O., Shumilov A.: Podnoszenie jakości tarcz turbiny gazowej poprzez udoskonalenie technologii ich obróbki, Technologiczne Centrum, 15 (2014) 4-8.

[2] Shumilov A., Dvirna O.: Technologiczne sposoby podnoszenia jakości powierzchni połączeń zamkowych w elementach turbiny gazowej, NUBO, (2005) 175-176.

[3] Shumilov A., Dvirna O.: Współczesne metody obróbki zębów zamkowych w tarczach zespołu turbiny gazowej, NUBO, (2011) 112-115. 
[4] Beziyazychny V., Volkov S., Fomenko R.: Techniczne i ekonomiczne uzasadnienie technologii obróbki jodełkowych rowków tarczy silnika turbogazowego, СТИН, 2 (2008) 27-31.

\section{ANALYSIS OF APPLIED TECHNOLOGIES OF SURFACE TREATMENT LOCKS GRAPE COMPRESSOR AND TURBINE}

\section{S u m m a r y}

The surfaces of the lock connection elements in the turbine and compressor are one of the most stressed surfaces during operation of the turbine engine. The aggressive environment (hot gas with ashes and additives in fuel), high working temperature and pressure, loads caused by the existing centrifugal forces and forces of gas flow, vibrations - all these factors cause increase of variable loads and surface stresses, activation of fretting wear processes, fatigue cracking, erosion and other dangerous processes which often lead to destruction of lock connection, and even to fault of turbine motor. The most commonly used connection of turbine blade with the compressor rotors disc is the trapezoid lock, also called the dovetail, while in turbines the herring-bone lock connections are commonly applied. In course of the design and production of such a lock, and aiming to ensure faultless operation of the compressor and turbine rotor unit, as well as long service life of the whole motor, the following items shall be considered: high requirements to the composition and quality of the disc lock and blades, low workability of these materials, complicated shape and high requirements of precision and mutual arrangement of surfaces, along with the quality of lock surface. Such requirements may be met through the application of various machining methods (draw-out, milling), methods of electro-chemical (ECM) or electro-erosive (EDM) processing. The method of lock electro-chemical processing has a number of advantages in comparison to machining: the possibility to process the conductive materials with various mechanical features, ensuring high-quality surface layer, high productivity with a long electrode service life and its moderate cost. However, ECM processing precision is very low. Therefore, application of the draw-out method remains one of the most commonly used, and at the finishing stage it is even the only possible method to obtain hiprecision lock with a high quality surface layer.

Keywords: lock connections, form precision, surface layer quality, disc draw-out, turbine motor service life

DOI: 10.7862/rm.2018.37

Otrzymano/received: 24.04 .2018

Zaakceptowano/accepted: 10.10 .2018 